\title{
La energía distribuida como modelo post-fósil en Argentina
}

\section{Distributed energy as a post-fossil model in Argentina}

Martín KaZimierski*

\begin{abstract}
In Argentina, the installation of large solar and wind farms has increased the participation of renewable energy in the matrix, contributing to the goals of national diversification and dephosilization, although without altering the dominant structures of the traditional system. This work argues that it is possible to think about these energies' penetration as triggers of new public-citizen experiences, based on local management. From the analysis of three key actors: public companies, cooperatives and citizens; this paper explores the potential of distributed generation to drive a true energy transition, towards a more decentralized, deconcentrated and democratic model.
\end{abstract}

Keywords: energy transition, renewable energy, distributed generation.

\section{Resumen}

En Argentina, la instalación de grandes parques solares y eólicos ha incrementado la participación de la energía renovable en la matriz energética, contribuyendo a las metas de diversificación y desfosilización nacional, aunque sin alterar las estructuras dominantes del sistema tradicional. Este trabajo sostiene que es posible pensar la penetración de estas energías como disparadores de nuevas experiencias público-ciudadanas basadas en la gestión local. A partir del análisis de tres actores clave: empresas públicas, cooperativas y ciudadanos, el trabajo explora la potencialidad de la generación distribuida para traccionar una verdadera transición energética, hacia un modelo más descentralizado, desconcentrado y democrático.

Palabras clave: transición energética, energías renovables, generación distribuida.

\section{Introducción}

* Universidad de Buenos Aires, Conicet, correo-e: martin.kazimierski@gmail.com 
El sistema energético argentino actual enfrenta varios desafíos interconectados y multifacéticos, con causas financieras, técnicas, estructurales y sociopolíticas. Uno de los mayores retos es la dependencia alta hacia los combustibles fósiles, básicamente petróleo y gas, que actualmente representan $87 \%$ de la oferta energética y $66 \%$ de la oferta eléctrica total (Martínez y Porcelli, 2018); otro es el déficit energético, cuyo origen se remonta a mediados de la década del 2000 , pero que adquirió una dimensión muy significativa en el decenio siguiente, partiendo de una dificultad sectorial para convertirse en un problema de impacto macroeconómico (Goldstein et al., 2016) ${ }^{1}$. Frente a este contexto, y ante la necesidad de una disminución drástica de emisiones de gases de efectos invernadero (GEI), el país enfrenta un gran desafío en la incorporación de fuentes alternativas y limpias.

En los últimos años, la tecnología de generación renovable, fundamentalmente eólica y solar, ha avanzado aceleradamente en el mercado eléctrico nacional. La puesta en marcha del programa RenovAr, en 2016, sentó las bases para la proliferación de proyectos de gran potencia conectados a la red de transmisión, con modelos de negocio que beneficiaron a las grandes empresas, pero que excluyeron a aquellos actores más pequeños, quienes encontraron numerosos obstáculos financieros para desarrollar estas infraestructuras de gran envergadura.

A nivel global y local es posible advertir experiencias donde la transición hacia energías renovables tiende también a un desplazamiento en la concepción de la energía en general, induciendo modelos más de tipo local o comunitario. Propuestas como la energía ciudadana en Alemania o los movimientos de autoconsumo en España remiten a la posibilidad de poner nuevamente en debate la posibilidad de fortalecer las opciones de generación más cercanas al consumo, y de pensar el pasaje de una dimensión societal pasiva respecto de la cuestión energética a una activa (Fornillo, 2017).

En esta línea, las energías renovables son cada vez más asociadas a un nuevo modelo basado en la denominada Generación Distribuida (GD). Este concepto no es en absoluto nuevo, y aunque no existe una única definición, en general se asocia a la generación que se ubica más próxima a los puntos de consumo, opuesto a lo que hoy sucede con las plantas de generación termoeléctrica, las centrales nucleares, o las grandes presas hidroeléctricas. Su definición puede variar, también, según el tipo de tecnología, la capacidad instalada, el impacto ambiental, o la titularidad.

\footnotetext{
${ }^{1}$ Solo el sector energético implicó $27.1 \%$ del crecimiento del gasto público, y más de US $\$ 30.000$ millones en salida de divisas entre 2010 y 2014, fundamentalmente, para la compra de gas natural, GNL, gasoil y fueloil (Goldstein et al., 2016).
} 
La Agencia Internacional de Energía (IEA, por sus siglas en inglés) considera como GD únicamente a la que se conecta a la red de distribución de baja tensión y la asocia a determinadas tecnologías. Para los Organismos Europeos de Normalización es aquella generación producida por instalaciones de menor tamaño que las centralizadas, habitualmente inferiores a $10 \mathrm{MW}$, mientras que para el Departamento de Energía de Estados Unidos de América (Department of Energy) se extiende a varias decenas de MW de potencia (IEA, 2018). A pesar de que la GD es independiente del tipo de tecnología, en este trabajo es concebida como instalaciones de energía renovable que se ubican próximos a los puntos de consumo, y que se conectan exclusivamente a la red de distribución, pudiendo ser su potencia de unos pocos $\mathrm{kW}$ hasta decenas de MW.

Este estudio se propone abordar las incipientes pero disruptivas experiencias de transición hacia modelos locales de generación eléctrica en Argentina, a partir de destacar la centralidad de tres actores clave: las escalas de gobierno más bajas (organismos provinciales y municipales), las cooperativas eléctricas y los propios usuarios de la red. Una anticipación de sentido es que estos actores constituyen potenciales agentes para motorizar una verdadera transición energética, que desafíe la explotación privada y los sistemas desterritorializados, propiciando un sistema más descentralizado y desconcentrado hacia modelos más eficientes, sustentables y democráticos.

Se abordan las provincias porque, desde la reforma constitucional de 1994, poseen el control de las reservas energéticas, lo que ha sido acompañado por la creación de empresas públicas y mixtas para explotarlos, en algunos casos con especial énfasis en el recurso solar y eólico; también tienen la potestad sobre sus redes de distribución eléctrica, aspecto clave para regular la conexión de la generación en baja tensión. Las cooperativas eléctricas por su parte se consideran porque una gran cantidad de éstas planea ampliar su participación en el mercado eléctrico (hoy como meros agentes de la distribución eléctrica), reapropiándose de la generación a través de proyectos renovables y distribuidos. Y en el caso de los usuarios de la red porque con la sanción de la ley 27.424, en 2017, tienen la posibilidad de convertirse en prosumidores, es decir, usuarios que, según las condiciones del día, pueden ser productores o consumidores netos de energía eléctrica.

De esta manera, la incorporación de esta tecnología abre un camino para la transformación del sistema eléctrico a través de una reconfiguración del mapa de actores y una nueva forma de organización de la política energética, que se daría no solo en términos federales, sino, y sobre todo, de manera local. 
La investigación comienza con un análisis crítico del actual proceso de incorporación de energía renovable en el país; continúa con uno pormenorizado de los tres actores que podrían traccionar nuevos modelos de generación público-ciudadana: empresas públicas, cooperativas y los propios usuarios de la red; y finalmete, teniendo en cuenta la importancia de estas dinámicas en términos de poder político-económico y su accionar en el territorio, para finalizar, se incluye una reflexión sobre la transición energética y su carácter geográfico, ponderando la necesidad de considerar relaciones multiescalares entre los diversos actores que operan sobre la cuestión energética y su potencial para viabilizar un sistema más descentralizado, desconcentrado, menos contaminante y más democrático.

\section{La energía renovable en un paradigma centralizado y concentrado}

Las apuestas por diversificar la matriz energética en el país, fundamentalmente a través de leyes y programas para la promoción de las energías alternativas (solar, eólica, biomasa, etc.), se han visto sistemáticamente obstaculizadas y pospuestas por coyunturas institucionales y macroeconómicas, conformando un escenario donde la participación de estas energías, para 2018, apenas cubría $1.9 \%$ del total de la demanda eléctrica nacional (CAMMESA, 2019).

Un antecedente cercano es la experiencia fallida con la sanción de la ley 26.190 (2007), que adoptaba la meta de 8\% de participación de fuentes renovables para el 2016, y el lanzamiento del programa Genren (Enarsa, 2009), donde sólo una quinta parte de los proyectos lograron concretarse. Más aún, esta situación se recrudeció ante el conjunto de transformaciones institucionales y políticas orientadas a la explotación de Vaca Muerta que desde 2012, con la sanción de la ley 26.741 (BORA, 2012) de soberanía hidrocarburífera y la expropiación de 51\% de las acciones de YPF, retroalimentaron una ilusión "eldoradista" sobre los recursos hidrocarburíferos.

Para entender el actual desarrollo de sistemas de energía renovable bajo la ley $27.191(2015)^{2}$ y el programa RenovAr (2016), impulsado por el gobierno de Mauricio Macri (2015-2019), es preciso partir de una transformación del mercado energético global. Las tecnologías renovables están mostrando un nivel de madurez y competitividad económica que las coloca entre las opciones más dinámicas del mercado.

\footnotetext{
${ }^{2}$ Reformula la ley 26.190, estableciendo nuevos plazos: $8 \%$ a fines de 2017 y $20 \%$ a fines de 2025. La mayor novedad de la nueva ley radica en que los grandes usuarios (más de $300 \mathrm{~kW}$ ) deberán cumplir dicho objetivo en forma individual. Para ello se concedieron tres opciones: contratación con un generador privado o comercializador, autogeneración, y compra conjunta con CAMMESA.
} 
Desde el 2010, el costo promedio de electricidad para proyectos de energía solar fotovoltaica disminuyó $73 \%$ para 2017 , así como $22 \%$ en el caso de la eólica (Irena, 2019), al tiempo que los denominados fondos verdes destinados a financiar proyectos en el Sur Global se multiplicaron aceleradamente.

El programa RenovAr ha logrado, en sus primeras tres rondas $(1,1.5$ y 2), adjudicar una potencia inédita hasta entonces. Se trata de 147 proyectos en 21 provincias, por un total de $4466.5 \mathrm{MW}$ (12\% del total), divididos en 41 proyectos solares, 34 eólicos, 18 de biomasa, 14 pequeños aprovechamientos hidroeléctricos, 36 de biogás y 4 de biogás de relleno sanitario. ${ }^{3}$ Su éxito puede atribuirse a las condiciones contractuales que conforman un marco más lucrativo para las empresas privadas. En este caso, la "preferencia de alimentación", es decir, la obligación de los operadores de las redes a dar preferencia a la electricidad generada por energías renovables y el "precio mínimo garantizado", que asegura a los generadores un precio de compra en dólares estable durante 20 años (Pendón et al., 2017) son dos aspectos destacados.

Se incluye además un cúmulo de beneficios fiscales y garantías de pago, los cuales disminuyen la incertidumbre asociada a la capacidad de pago de la Compañía Administradora del Mercado Mayorista Eléctrico S. A. (CAMMESA), encargada de coordinar los despachos y el funcionamiento del sector eléctrico en general. En este sentido, las garantías están respaldadas, en último término, por el Banco Mundial (Martínez y Porcelli, 2018); además existe un mayor acceso a financiamiento externo (con fondos chinos como protagonistas) e interno, como es el caso del Fondo para el Desarrollo de Energías Renovables (Foder) creado por la ley 27.191.

La incorporación de estas fuentes ha estado motivada por el reemplazo de combustibles fósiles cada vez más caros y escasos pero, principalmente, para atraer nuevas inversiones extranjeras que incrementen los ingresos de divisas en un contexto atravesado por el déficit comercial y un fuerte endeudamiento (Goldstein et al., 2016).

Más allá de que el programa RenovAr se inscriba dentro de los compromisos asumidos en el Acuerdo de París en 2015 (IPCC, 2016) para la reducción de emisiones GEI, y forme parte de los mecanismos de desarrollo sustentable, el hecho de que la cantidad de energía térmica licitada por el Estado, desde que se inició el programa, haya sido mayor a la renovable, da la pauta para considerar que la promoción de estas energías verdes no estuvo

\footnotetext{
${ }^{3}$ Estos se suman a los 49 proyectos por un total de 1164,4 MW adjudicados por el mercado a Término de Energía Eléctrica de Fuente Renovable (MATER), que son contratos celebrados entre generadores y grandes usuarios del Mercado Eléctrico Mayorista (MEM).
} 
motivada por una política ambiental genuina, sino por garantizar la renta energética a los grandes actores globales del campo de la energía renovable.

Según datos de CAMMESA, para el periodo 2015-2019, la potencia termoeléctrica instalada se incrementó en $4808 \mathrm{MW}$ y en $1838 \mathrm{MW}$ la renovable. Entonces, la política energética no estuvo orientada a transformar la disposición espacial y los patrones de poder que rigen el sistema, sino a reforzar el esquema concentrado y centralizado fosilista, pero con nuevas fuentes renovables.

Tal como describió el sociólogo Lewis Mumford (1977), la generación, transformación, y transporte de energía fósil, en la mayor parte de su historia desde la era industrial, se ha caracterizado por una tendencia hacia el aumento de escala y hacia la centralización geográfica y política. En el umbral del siglo XXI, las energías renovables aparecen replicando este modelo pero bajo el velo del capitalismo verde (Hawken et al., 1999) y el crecimiento verde (World Bank, 2012), que implican una producción de energía limpia y sustentable con la misma lógica de producción en masa de un producto para un mercado de consumo homogéneo.

Esta dinámica mercantilizadora, concentradora y "extranjerizadora" de la energía se exacerba aún más cuando desde el Estado se promueve la importación masiva de componentes, invitando incluso a las corporaciones más grandes a aterrizar en el país a través de grandes beneficios fiscales, sin inducir una participación social o estatal en la generación de energía, menos aún la creación de una industria energética local.

Si bien una gran porción de inversores del programa RenovAr corresponde a agentes del empresariado nacional, estos actúan más bien como intermediarios al importar la mayor parte del capital y la tecnología. De los 4466.5 MW licitados, 24.7\% fue adjudicado a empresas de capitales europeos, con las españolas a la cabeza (12.9\%), mientras que los capitales chinos aportaron 16.7\%, y los fondos de inversión de Estados Unidos de América 7.6\% del total (Verbitsky, 2019) ${ }^{4}$.

Esta participación inicial ha variado luego con el ingreso masivo de actores financieros-especuladores, lo cual ha implicado cambios en la estructura de propiedad, siempre en favor de los grandes jugadores. Incluso, a partir de la ronda 2, hubo cambio en el marco normativo que promovió la instalación de tecnólogos extranjeros para ensamblar en Argentina, como fue el caso de la danesa Vestas.

La entrada de estos actores transnacionales podría explicarse por la necesidad del país de establecer una balanza de capitales positiva, ya sea a través de préstamos o como inversión extranjera directa (IED), lo que

${ }^{4}$ Entre los capitales nacionales, Genneia S. A., de Fides Group, fue la de mayor adjudicación con $7.6 \%$ (Verbitsky, 2019). 
podría ser una política aceptable si se tratara de una transferencia tecnológica (el denominado know-how), que generara los recursos externos para cubrir sus futuros retiros, es decir, si la inversión trajera aparejado un aumento de las exportaciones o una sustitución de importaciones, pero la realidad indica que el proceso de incorporación de energías renovables impulsado por el gobierno nacional se presenta, más bien, como un agente dinamizador de las fuerzas productivas $y$, sobre todo, financieras, brindando la posibilidad de que los actores privados, en términos de Schumpeter (1957), logren establecer un monopolio innovador transitorio que les permita internalizar ganancias extraordinarias, avalados también por un halo ecológico que viabiliza la construcción de legitimidad.

En este marco, el país desaprovecha la oportunidad de sentar las bases de una transición hacia nuevos modelos energéticos. Pensar esto es ir más allá de cambios cuantitativos en la matriz energética, del reemplazo de combustibles fósiles contaminantes y finitos, por otros limpios e inagotables: se trata de concebir a las tecnologías de energía renovable como motores de un nuevo paradigma energético, involucrando generación descentralizada y de baja potencia (microgeneración), capacidad de almacenamiento expandida, demanda más eficiente $y$, en última instancia, planeamiento de abastecimiento a través de flujos inteligentes de datos en tiempo real, más conocidos como redes inteligentes de distribución (o smart grids, en inglés).

En este sentido -a diferencia de los hidrocarburos que se encuentran desigualmente distribuidos y requieren una gran inversión y métodos de transformación-, la energía solar y eólica tienen la característica de aprovechar el flujo biológico de la naturaleza para generar electricidad en cualquier punto de la superficie terrestre: tienen la capacidad de alterar las condiciones hegemónicas que caracterizan al sector energético, impulsando la descentralización geográfica de la matriz, lo que podría implicar también la desconcentración económica y política de los agentes del sistema, alentando una democratización del sector energético a través del empoderamiento de los territorios y de los propios usuarios del sistema, quienes tendrían la posibilidad de acceder al recurso, e incluso convertirse en agentes vendedores del mercado.

Si bien la GD refiere a una opción técnica y tecnológica, antes que política, es claro que esta podría generar condiciones para desarrollar el uso de fuentes de energías renovables y a la vez cuestionar el modelo centralizado predominante. En Argentina, este modelo ha avanzado históricamente en zonas aisladas (off the grid), donde esta tecnología representa la única posibilidad de acceso a la energía eléctrica para los pobladores, pero para que el impacto sea relevante la GD debe llegar donde los consumos son más importantes, es decir, los centros urbanos. A continuación, se 
hará un análisis de las experiencias incipientes de desplazamiento hacia modelos locales de GD, motorizados por tres actores o escalas: organismos provinciales y municipales, cooperativas eléctricas y los usuarios de la red.

\section{Generación distribuida para disminuir la vulnerabilidad energética}

La evolución histórica del sistema eléctrico nacional, sumado al control provincial de las reservas energéticas desde la reforma constitucional de 1994, ha consolidado grandes desigualdades regionales en la dotación de la infraestructura básica de generación y transmisión, potenciando la competencia interna por el aprovechamiento de los recursos energéticos hídricos e hidrocarburíferos y la instalación de grandes centrales de generación termoeléctrica y nuclear.

En consecuencia, el escenario actual presenta fuertes contrastes, observándose provincias y regiones ostensiblemente importadoras de energía y otras largamente exportadoras. Por caso, existe una fuerte demanda concentrada en la Región Metropolitana de Buenos Aires que, junto a otras aglomeraciones urbanas en las provincias de Santa Fe y Córdoba, representan dos tercios (66\%) de la demanda nacional (CAMMESA, 2019), éstas son abastecidas por regiones productivas relativamente distantes, lo que implicó, a lo largo del siglo XX, grandes inversiones en el levantamiento de infraestructura de gran escala, plazos extensos de trabajo y menor eficiencia del sistema.

Ya en los inicios del milenio esto representaba un problema, cuando la potencia de generación de Comahue (5327 MW) y el NOA (1713 MW) sobrepasaba la capacidad de transmisión a los puntos de consumo (4600 y $600 \mathrm{MW}$, respectivamente) (El Día, 2004). Más cercano en el tiempo, el histórico apagón del 16 de junio de 2019, que afectó a todo el territorio nacional y países limítrofes, expuso los riesgos que conlleva un sistema eléctrico fuertemente dependiente de su capacidad de transporte y de los corredores que conectan los grandes centros de generación con los de consumo.

El mapa 1 da cuenta de estas disparidades energéticas regionales para el periodo 2015-2018. ${ }^{5}$ Según datos provistos por CAMMESA, regiones como Comahue y Noreste ostentan un saldo energético ampliamente

\footnotetext{
${ }^{5}$ El mapa 1 resalta en tonos claros las regiones con saldo energético negativo, es decir, que consumieron más de lo que generaron, mientras que las regiones superavitarias, que generaron más de lo que consumieron, se representan en tonos más oscuros. El cálculo se realizó dividiendo los MWh generados por los MWh consumidos para el periodo comprendido, el valor "1,00" representa el punto de equilibrio.
} 


\section{Mapa 1 \\ Saldo energético por región (2015-2018)}

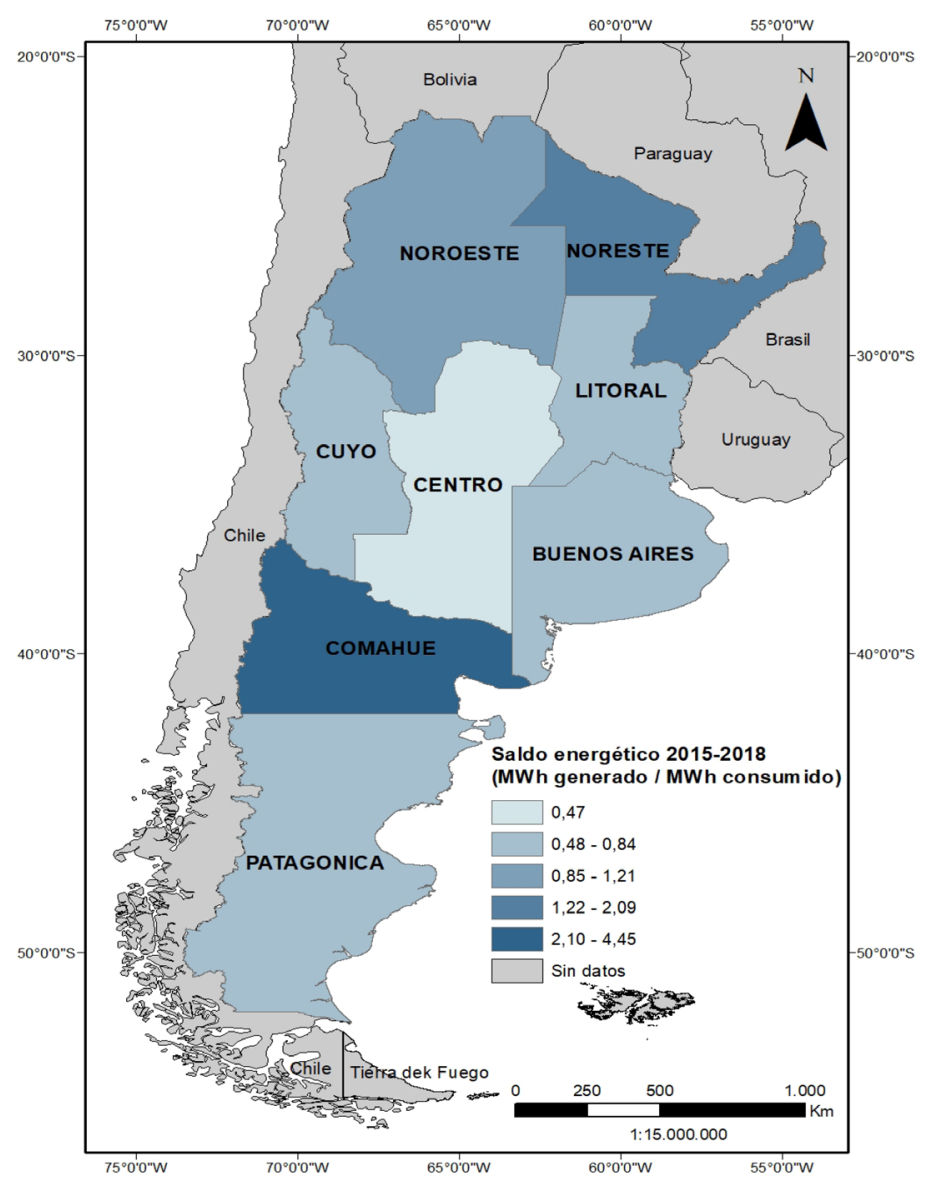

Fuente: elaboración propia con datos de CAMMESA (2019).

superavitario. El primero generó cuatro veces más energía de la que consumió, en tanto la región Noreste duplica esa relación; al contrario, la región Centro apenas genera la mitad de lo que consume, seguido de Cuyo, que cubre $75 \%$ de su demanda. Las regiones Patagónica y Litoral, junto a la provincia de Buenos Aires, ostentan un saldo negativo, aunque alcanzan más de $80 \%$ de cobertura, mientras que la región Noroeste es la única cuyo consumo es análogo a su generación.

Así, provincias netamente deficitarias como Córdoba, San Juan y La Pampa se ven subordinadas a la capacidad de transporte y a las decisiones que exceden a su jurisdicción, mientras que las provincias exportadoras como Neuquén y Río Negro han de beneficiarse de la actividad energética, 
aunque con ciertos matices. La construcción de megarepresas que alimentan el sistema nacional comprendieron la intervención radical del ciclo biológico natural de sus cuencas hídricas, con consecuencias sociales y geopolíticas considerables (afectación del hábitat, desplazamientos de comunidades, conflictos interjurisdiccionales, entre otros).

Un caso icónico se presenta en la demanda histórica iniciada por el estado provincial de La Pampa hacia su par mendocino, vinculada al aprovechamiento hidroeléctrico del río Atuel. En esta línea, la instalación de centrales nucleares en la localidad de Lima en Buenos Aires, cuya participación es significativa en la matriz nacional y provincial, ha encontrado fuertes resistencias en la población y grupos ambientalistas. Asimismo, más allá del sistema eléctrico, las apuestas por actividades extractivas que refuerzan el paradigma fósil, como la explotación de hidrocarburos no convencionales en Neuquén a través del fracking, implican una utilización intensiva del territorio y el agua, y el consecuente desplazamiento de otras economías o formas de apropiación del territorio.

Contrario a lo descrito anteriormente, las energías renovables se benefician de una distribución geográfica más equitativa del recurso, cuyo aprovechamiento implica una menor intervención del territorio y una reducción de la infraestructura de transporte, es decir, menor pérdida de energía (estimadas entre 8 y el 15\%) y mayor eficiencia en las redes. Esto configura una fuerte sinergia con las propuestas de desarrollo de GD. A favor, la mayoría de las provincias argentinas presentan condiciones óptimas para el desarrollo de algún tipo de fuente. Por ejemplo, la región patagónica, en las provincias de Santa Cruz, Chubut y Río Negro, además de Buenos Aires, concentran el mayor potencial eólico, con vientos de calidad internacional de hasta 9-12 m/s (Pendón et al., 2017).

En el caso de la energía solar fotovoltaica, su potencial es aprovechable a lo largo de todo el territorio argentino, a excepción de las provincias más australes, presentando valores por encima de los $1.5 \mathrm{MW}$ h/m2/año; se destacan las regiones Noroeste y Cuyo en las provincias de San Juan, La Rioja, Catamarca, Tucumán, Salta y Jujuy (Porcelli y Martínez, 2018), además, existe un potencial sin explotar de la biomasa y el biogás, a partir de la actividad agropecuaria en las extensas y fértiles tierras de las regiones Centro y Pampeana.

No obstante, la existencia de condiciones propicias o habilitantes para la penetración de las energías renovables va más allá de la simple calidad del recurso. En comparación con la generación fósil, las renovables tienen una alta incidencia de costos de capital iniciales sobre los costos de operación, haciendo la viabilidad de tales proyectos particularmente sensibles al costo del capital (Pendón et al., 2017). Esto provoca que su desarrollo 
tenga un estrecho vínculo con el acceso al financiamiento y la calidad institucional nacional y provincial.

La particularidad del mercado energético contemporáneo es que algunos estados provinciales tienden a fomentar autónomamente la incorporación de fuentes renovables a través de un número significativo de empresas de energía público-provinciales, entre las que destacan: Servicios Energéticos del Chaco Empresa del Estado Provincial (SECHEEP), Empresa Provincial de la Energía (EPE) de la provincia de Santa Fe, Empresa Provincial de Energía de Córdoba (EPEC), Empresa Provincial de Energía del Neuquén (EPEN), Jujuy Energía y Minería Sociedad del Estado (JEMSE) y la Empresa Energía Provincial Sociedad del Estado (EPSE) en San Juan.

El propósito de estas empresas públicas se asocia no solo a intereses económicos, sino también a necesidades sociales y estratégicas, por ejemplo: la política industrial, el desarrollo regional y el suministro de bienes públicos. A diferencia de las empresas privadas, que se caracterizan por la implacable búsqueda de la maximización de los beneficios y del valor para los accionistas, de la propiedad pública se espera maximizar el beneficio para la sociedad mediante una asignación de recursos eficiente.

Las provincias que buscan salir del presente estado de vulnerabilidad energética y garantizar la seguridad en el servicio buscan contribuir al aprovechamiento de los recursos renovables locales e incentivar y respaldar iniciativas descentralizadas, para ello promueven normas, medidas, programas y proyectos que estimulen o exijan el uso de energías renovables. ${ }^{6}$ Por ejemplo, en Santa Fe la Empresa Provincial de Energía (EPE) licitó $50 \mathrm{MW}$ de energía solar y eólica para reforzar los puntos débiles de su infraestructura (Torres, 2019). Al tratarse de pequeñas centrales, el plan apunta mayormente a inversores locales más que a las grandes compañías que actúan en el programa RenovAr. En esta misma línea, la Empresa Provincial de Energía de Córdoba (EPEC) también planea avanzar en proyectos solares y de biomasa, este último a partir de cáscara de maní y residuos de poda, incluyendo a los propios municipios en el plan, a modo de asegurarse esos recursos (Singh, 2018a).

En Chaco, SECHEEP prevé licitaciones para el desarrollo de parques fotovoltaicos que reemplacen los generadores diésel altamente contaminantes (Singh, 2018b). Estos casos se replican de manera diferenciada también en provincias como Buenos Aires, Entre Ríos y San Juan. En Mendoza, el estado local ha creado un mercado a término provincial, es

\footnotetext{
${ }^{6}$ Los primeros parques de gran escala conectados al SADI tuvieron como protagonistas al Estado nacional y a las provincias como impulsores: "Vientos de la Patagonia I" en 2010, proyecto de ENARSA (80\%) en asociación con la provincia de Chubut (20\%), y la Planta Piloto de Generación Fotovoltaica "San Juan I" (2011), desarrollado por la empresa Energía Provincial Sociedad del Estado (EPSE) de San Juan, que actualmente es el responsable de su funcionamiento y mantenimiento.
} 
decir, un espacio donde la provisión de energía se puede comercializar entre privados dentro del entorno provincial, sin necesidad de participar en el MEM, de competencia nacional (Singh, 2019a).

Por otra parte, algunos municipios también han traccionado sus propios proyectos a través de desarrollos propios o mediante licitaciones, en la localidad entrerriana de Cerrito, a través del programa PROBIOMASA, el municipio ha encarado la construcción de biodigestores para transformar los residuos sólidos orgánicos urbanos en biogás - para generación eléctrica y para su combustión en cocinas- y biofertilizante (Carrizo et al., 2014). En la misma provincia, la localidad de Gualeguaychú impulsa un parque solar fotovoltaico de $50.2 \mathrm{~kW}$ (Singh, 2019b).

Este marco, sin embargo, contrasta fuertemente con la participación directa de estas empresas públicas en el programa RenovAr, donde su rol ha sido más bien marginal, limitado a la cesión de terrenos sin ningún tipo de control sobre la planta una vez operativa. En definitiva, se adjudicaron sólo 13 proyectos de propiedad pública: 10 solares (JEMSE, EPEC, y EMESA, de Mendoza) y tres pequeños aprovechamientos hidroeléctricos (EPEC).

Algunos desarrollos han experimentado una fuerte oposición alegando que no reditúan beneficios a las localidades en que se instalan estas industrias e incluso que las afectan de manera directa. Casos como el de JEMSE, en Jujuy -con los mega-parques fotovoltaicos Cauchari I, II y III, con un total de $300 \mathrm{MW}$ de potencia- se desarrollaron con un profundo endeudamiento y acuerdos inusitados con el Gobierno Nacional ${ }^{7}$.

En La Rioja, la construcción del Parque Solar Nonogasta, de la empresa 360 Energy y Fides Group, trajo aparejados cuestionamientos desde algunos sectores políticos, quienes alegaron que la autorización por parte del gobierno provincial a su conexión sin costo con la línea de alta tensión La Rioja-Nonogasta limitaría la capacidad de explotación futura por parte de la provincia (Energías Renovables, 2017).

En esta línea, la tercera ronda del programa RenovAr, inicialmente estimada para el año 2018, debió ser pospuesta fundamentalmente por dos razones: por un lado, las dificultades para conseguir financiación ante la profundización de la crisis económica y cambiaria que atraviesa el país; y por otro, la saturación en las líneas de alta y extra tensión que forman el Sistema Interconectado Argentino (SADI), en parte por la entrada de

${ }^{7}$ La polémica del proyecto Cauchari radica en que los costos de las nuevas líneas de transmisión requeridas para despachar lo generado por el parque, estimados en 50 millones de dólares, serían asumidas por el Estado Nacional en lugar de la provincia. Asimismo, el proyecto, donde JEMSE posee una participación de $80 \%$ (el 20\% restante es propiedad de Power China, Shanghai Electric y Talesun), implicó un aporte de $85 \%$ por parte del banco chino Eximbank, mientras que la provincia aporta $15 \%$ restante, financiado a través de bonos provinciales "verdes", que significaron un endeudamiento por 210 millones de dólares (Porcelli y Martínez, 2018). 
los megaparques de las rondas 1 y 2. Finalmente, la ronda 3 se llevó a cabo en 2019, pero contemplando solo proyectos de menor escala, de hasta $10 \mathrm{MW}$ de potencia, con un tope de $400 \mathrm{MW}$ en todo el país, los cuales debieron contemplar su conexión a redes de distribución eléctrica de media tensión.

De esta manera, un adecuado planteamiento de la política energética en el ámbito provincial supone disminuir la dependencia a través de una gestión de provisión eficiente de energía renovable basada en la participación inclusiva y proactiva de todos los actores del territorio y la sostenibilidad del ecosistema. Más aún, en la dimensión económica, las provincias están ante la posibilidad de saldar las disparidades energéticas que afectan sus balanzas fiscales, generando su propia energía y de este modo ahorrando en importarla.

Incluso podría pensarse en programas públicos en los que el ahorro de la importación de energía se reinvierta en nueva generación, esto reforzaría el abastecimiento local, incrementaría los recursos exportables y disminuiría los impactos ambientales, además de significar un ahorro en el gasto en transporte. En definitiva, se trata de avanzar hacia la denominada seguridad energética, término que alude al autoabastecimiento o, más aún, a la idea de la soberanía energética.

\section{Generación distribuida para el desarrollo local y comunitario}

Hasta aquí, la GD se ha destacado por su potencialidad para descentralizar el sistema energético, atribuyendo un mayor poder de decisión a las escalas de gobierno intermedias y bajas, y permitiendo el aprovechamiento in situ de los recursos locales. Ahora bien, el concepto "distribuido" remite al supuesto de que la energía es naturalmente centralizada, un atributo por demás engañoso. Desde la primera mitad del siglo XX existen ejemplos que nos permiten hablar de una generación autónoma y comunitaria de energía, desvinculada del ámbito nacional y los sectores hegemónicos.

Según datos provistos por la Secretaría de Energía, en la década de los sesenta, la potencia instalada de autoproducción representaba alrededor de $30 \%$ del total, protagonizado mayormente por cooperativas eléctricas que surgieron en pequeñas localidades. En las décadas siguientes su participación entraría en franco declive, conforme se expandía el SADI: en el año 1970 la participación fue de $20 \%$ y $10 \%$ a fines de la década de 1980, hasta llegar al mínimo de 7\% a fines de los noventa (Furlán, 2017). No obstante, desde entonces, la autoproducción ha recuperado terreno de la mano de cooperativas, las cuales han desplegado estrategias que reorientan su campo de acción en la generación eléctrica. 
En la actualidad funcionan casi 600 cooperativas que brindan el servicio eléctrico en el país, concentradas mayormente en las provincias de Santa Fe, Córdoba y Buenos Aires (Vitale, 2010), éstas representan $11.64 \%$ del consumo nacional, $30 \%$ del mercado si se descuenta el AMBA y 58\% tomando solo las zonas rurales (Garrido et al., 2013); aunque su rol se limita a la distribución, hasta mediados de la década de los sesenta tenían una participación preponderante en la generación eléctrica, ya que operaban en territorios desconectados del sistema.

La posterior extensión de la red de transmisión nacional y el levantamiento de una infraestructura de mayor capacidad y potencia de generación significó la caída en los volúmenes de energía producidos por las cooperativas, principalmente por el incremento de los costos de generación y mantenimiento de los equipos, así como el aumento de las erogaciones por la compra de energía al sistema (Carrizo et al., 2014), esta situación debilitó la autonomía de las cooperativas, que debieron abandonar su actividad en la producción para limitarse a la distribución, además de una gama amplia de servicios comunitarios alternativos. ${ }^{8}$

A pesar de ello, hoy en día existe una gran cantidad de cooperativas que apuestan por reapropiarse de su generación a través de proyectos renovables, principalmente eólicos, solares y de biomasa. Ya desde la década de los noventa habían demostrado su interés desarrollando los primeros parques eólicos del país en el sur de la Provincia de Buenos Aires (Carrizo et al., 2014), aunque luego entrarían en una etapa de estancamiento. ${ }^{9}$ Para el 2008, sólo 10 cooperativas eléctricas distribuidas en cuatro provincias (Buenos Aires, Chubut, La Pampa y Neuquén), explicaban el $100 \%$ de la potencia renovable instalada en el país (Garrido et al., 2013), pero desde el 2007 la Federación Argentina de Cooperativas Eléctricas (FACE) ha retomado con fuerza el desarrollo de proyectos renovables impulsando para ello el proyecto Generación Eléctrica de Cooperativas Integradas (GECI), al que se han sumado algunas federaciones regionales, como las de Buenos Aires (Fedecoba), Córdoba (Fecescor), Santa Fe (Fescoe), Misiones (Fecem), entre otras.

Un aspecto a destacar de esta iniciativa es la alta participación de cooperativas en proyectos de generación a partir de biomasa y biogás, aprovechando los residuos que genera la actividad agropecuaria en zonas predominantemente rurales. Por ejemplo, hasta 2015, el programa provincial de Buenos Aires Proinged financiaba 15 proyectos de generación

\footnotetext{
${ }^{8}$ Algunas cooperativas fueron absorbidas por empresas públicas nacionales y provinciales, mientras que otras se expandieron para brindar nuevos servicios: agua corriente, cloacas, pavimentación, funeraria, telefonía, televisión por cable, internet, entre otros.

${ }^{9}$ Las condiciones macroeconómicas del país hicieron que de los 10 proyectos desarrollados entre 1994 y $2001(24,700 \mathrm{~kW})$ se sumaran solo tres en el nuevo milenio, mientras que los existentes empezaron a sufrir problemas en su operación (Garrido et al., 2016).
} 
distribuida, de los cuales 11 estaban impulsados por cooperativas eléctricas: ocho de biomasa, dos eólicos y un pequeño aprovechamiento hidroeléctrico (Castelao Caruana, 2016). ${ }^{10}$

En el caso de la cooperativa de Rojas (Clyfer), la entidad logró adjudicar en RenovAr (ronda 2) su proyecto de biomasa a partir del residuo del marlo y la chala del maíz de $7 \mathrm{MW}$ y tiene intenciones de expandirse a generación solar y eólica. ${ }^{11}$ En esta línea, la Federación de Cooperativas Eléctricas de Córdoba (Fecescor), junto con la Empresa Provincial de Energía de Córdoba (EPEC), apuestan por un desarrollo regional del biogás en el sector rural, para lo que han lanzado un plan para que más de 3,000 tambos generen su propia energía bajo el Programa de Servicios Agrícolas Provinciales (Prosap).

Cabe destacar que aunque los proyectos de biomasa y biogás forman parte de la transición hacia un sistema más descentralizado, se inscriben en una agenda que va más allá de reemplazar las fuentes de generación eléctrica. Se trata de crear valor agregado en origen, e impulsar lo que se denomina la "economía circular", una estrategia que tiene por objetivo reducir tanto la entrada de los materiales como la producción de desechos vírgenes, cerrando los flujos económicos y ecológicos de los recursos. Esto industrializa la ruralidad y empodera a los actores locales, es decir, a la comunidad, a las cooperativas y a los municipios.

En cuanto a iniciativas de energía solar y eólica, destaca el desarrollo del parque eólico Antonio Morán, inaugurado en 1994 con una potencia instalada de $16 \mathrm{MW}$, perteneciente a la Sociedad Cooperativa Popular Limitada de Comodoro Rivadavia, éste fue el parque más grande de América Latina durante varios años y el más grande de Argentina hasta la puesta en marcha del Parque eólico Arauco en La Rioja, en 2011.

En la actualidad existen proyectos avanzados e integrales como el que lleva adelante la Cooperativa de Provisión de Obras y Servicios Públicos y Crédito Limitada en la localidad de Armstrong, en Santa Fe, un piloto que involucra un parque solar, microgeneración y desarrollo de una red eléctrica "inteligente"; otras experiencias similares son impulsadas por la Cooperativa de Trenque Lauquen y la Cooperativa Eléctrica de Godoy Cruz, que, junto con la Empresa Mendocina de Energía S. A. (EMESA), desarrollaron el parque solar PASIP de 1.5 MW en San Martín (Guido y Carrizo, 2016).

\footnotetext{
${ }^{10}$ Se trata de las cooperativas de 9 de julio, Saladillo, Rojas y Parada de Robles. El objetivo de Proinged es reemplazar gran parte de los motores diésel que operan en la provincia con $500 \mathrm{MW}$ de parques solares.

${ }^{11}$ Además, la provincia de Buenos Aires, a través de Proinged, estudia mecanismos para que cooperativas, usuarios particulares, barrios privados, grandes fábricas y pymes, puedan construir granjas de energía eólica (Porcelli y Martínez, 2018).
} 
También hay iniciativas incipientes como el de la cooperativa de Rojas (Clyfer), que procura la instalación de paneles solares fotovoltaicos donados por la Universidad Nacional de San Martín y de dos aerogeneradores (Carrizo et al., 2014), el de la Cooperativa Eléctrica de Río Grande que, en conjunto con la Universidad Nacional de Tierra del Fuego, lleva adelante el proyecto experimental Energía Eólica en Tierra del Fuego (Singh, 2019c) o el de la Cooperativa de Electricidad Bariloche Ltda (CEB) (Singh, 2019d).

El programa RenovAr les brindó reducidas oportunidades a las cooperativas: sólo siete han recibido proyectos en las diferentes rondas de licitación (con capacidades que van desde 1.2 hasta $7 \mathrm{MW}$ ). La importación de componentes, repuestos y recursos para el mantenimiento, significó un importante aumento del presupuesto operativo, recursos económicos del que la mayoría de las cooperativas eléctricas no disponen. Esto deja al descubierto las limitaciones que presentan este tipo de proyectos cuando no se desarrollan políticas para generar capacidades técnicas locales (Garrido et al., 2013).

Un informe publicado por Irena (2018: 5) concluyó que las políticas podrían tratar de "evitar la discriminación contra los inversores más pequeños y basados en la comunidad, e idealmente podrían crear un acceso equitativo al mercado para todos los participantes del mercado". Una de las opciones que se encuentran estudiando las cooperativas es la posibilidad de entrar en el mercado a término, es decir, vender energía limpia a aquellos grandes usuarios (consumo igual o mayor a $300 \mathrm{KW}$ ), quienes, de acuerdo a la ley 27.191, deberán utilizar en forma creciente energías limpias, comenzando en $8 \%$, en 2019, y hasta alcanzar $20 \%$, en $2025 .{ }^{12}$

De esta manera, en un contexto de déficit energético, en el que los proyectos provinciales y nacionales tardan en ejecutarse, actores locales desarrollan iniciativas y proyectos innovadores que abren las puertas a un nuevo debate asociado a la problemática energética local y la construcción de políticas. Las tecnologías de energía distribuida, y su gestión comunitaria, tienen la potencialidad de crear las condiciones materiales que permitan el surgimiento de los bienes comunes de energía, en contraste con los modelos tradicionales centralizados de generación energética que se han desarrollado y consolidado en el transcurso del siglo XX. Esto no sólo favorece al ambiente, sino sobre todo a la comunidad, dinamizándola e incrementando la generación de valor agregado y los ingresos tributarios locales; se fomenta también la participación de los usuarios en la construcción de las tecnologías y las decisiones energéticas.

\footnotetext{
${ }^{12}$ Hasta ahora solo empresas privadas han entrado en este negocio. Incluso existen casos de grandes compañías ajenas al sector renovable que han desarrollado sus propios parques eólicos para autoconsumo y venta de energía, como Aluar I (50.4 MW) en Buenos Aires, propiedad de la compañía de aluminios, y Manantiales Behr (99 MW) de YPF.
} 
Hoy en día, por ejemplo, las tarifas están condicionadas según el contexto particular técnico y político de cada distribuidora y, en la mayoría de los casos, los usuarios no acceden a la información o no comprenden su estructura. ${ }^{13}$ Entonces, la generación comunitaria puede ser un camino en la descentralización de las políticas energéticas, arrebatando la cuestión de la mano de los especialistas y los negocios para pasarlo a manos de la gente. Solo así, estaríamos ante una transición que, más qué energética, es socio-energética: un pasaje hacia una sociedad comunitaria, autónoma y autoorganizada.

\section{Generación distribuida para el empoderamiento ciudadano}

Para una verdadera revolución energética, no basta con la proliferación de parques eólicos y solares distribuidos en el sistema energético, sino que se requiere una verdadera participación popular en el mismo. En este sentido, hasta ahora el usuario final ha desempeñado un papel pasivo en el sistema energético: cautivo de las empresas distribuidoras y las oscilaciones tributarias para poder acceder a un servicio que hoy se presenta imprescindible. No obstante, en los últimos años se han consolidado numerosos hitos que propugnan un cambio de paradigma energético y un empoderamiento de la masa societaria.

La sanción de la Ley $\mathrm{N}^{\circ}$ 27.424, en diciembre de 2017, de Régimen de Fomento a la Generación Distribuida de Energía Renovable Integrada a la Red Eléctrica Pública $(B O R A, 2017)$ constituye el primer gran paso a nivel nacional hacia nuevos modelos energéticos descentralizados. La ley establece las condiciones jurídicas y contractuales para que los usuarios residenciales de la red puedan generar su propia energía para autoconsumo, lo que se denomina "microgeneración", e inyectar los excedentes a la red. Obliga a los distribuidores a facilitar dicha inyección, asegurando el libre acceso a la red de distribución y crea la figura del "usuario-generador", excluyendo expresamente a los grandes usuarios y autogeneradores del Mercado Eléctrico Mayorista (MEM) ${ }^{14}$ también crea el Fondo para la Generación Distribuida de Energías Renovables (Fodis), destinado al otorgamiento de préstamos, incentivos, garantías, la realización de aportes de capital y adquisición de otros instrumentos financieros, con el Estado nacional como autoridad de aplicación. ${ }^{15}$

\footnotetext{
${ }^{13}$ El valor de las tarifas está compuesto por más de 20 impuestos municipales, provinciales y nacionales.

${ }^{14}$ Estos actores del MEM están comprendidos por la Ley № 27.191 (BORA, 2015).

${ }^{15}$ El patrimonio del Fodis se constituye mediante aportes del Tesoro, que no podrán ser inferiores a $50 \%$ del ahorro en combustibles fósiles obtenido en el año previo debido a la incorporación de GD.
} 
Asimismo, paralelamente, en algunas provincias se ha avanzado en legislaciones locales de microgeneración, o se encuentran elaborado las normativas correspondientes. Un caso paradigmático es la provincia de Santa Fe, que fue pionera en habilitar la conexión a la red de sistemas residenciales en 2013 y hoy se encuentra a la vanguardia a nivel nacional. Desde 2016 lleva a adelante su propio programa de incentivos denominado "Prosumidores", el cual busca fomentar la adopción de soluciones fotovoltaicas de generación distribuida para los clientes de las compañías eléctricas locales, la Empresa Provincial de la Energía (EPE), y de las cooperativas eléctricas adheridas. A esta experiencia lo seguirían, más tarde, numerosas provincias, aunque bajo diversas estructuras y condiciones normativas: Mendoza, Ley $\mathrm{N}^{\circ} 7.822$ (BOPM, 2013); Salta, Ley de Balance Neto $N^{\circ}$ 7.824, (BOPS, 2014); San Luis, Ley $\mathrm{N}^{\circ} 921$ (BOSL, 2014); Neuquén, Ley N 3.006 (BOPN, 2016); Misiones, Ley de Balance Neto $\mathrm{N}^{\circ} 118$, (BOPM, 2016) y Jujuy, Ley $\mathrm{N}^{\circ} 6.023$, (BOPJ, 2017).

Cabe señalar que la generación de energía eléctrica, cualquiera sea su fuente, su transformación y transmisión, es de jurisdicción nacional: Ley $\mathrm{N}^{\circ} 15.336$ (BORA, 1960). Por el contrario, la distribución y el cobro corresponde a la jurisdicción provincial, remitiendo a la distribución de competencias entre el Estado federal y los estados provinciales sobre los servicios públicos. ${ }^{16}$ Esto ha generado, entre otras cosas, que en algunas provincias, la ineficiencia en la prestación del servicio, o diferentes regulaciones, hayan conformado tarifas dos a tres veces superiores a las vigentes en el ámbito nacional o en otras provincias. ${ }^{17}$

De lo anteriormente expuesto resulta que la microgeneración, en la medida que se conecta a la red de distribución para inyectar la energía excedente a la red, pertenece a la jurisdicción provincial, esto es, no participa de la interconexión interjurisdiccional ni interviene en los intercambios de energía eléctrica que se dan al nivel del MEM. Por ello, para que la ley nacional sea efectiva en cada jurisdicción, debe ser suscripta por los estados provinciales, lo que ha despertado ciertos debates al interior del país.

Desde diversos sectores políticos se argumenta que algunas de sus disposiciones exceden la jurisdicción federal, en particular la tarifa de incentivo y la autorización de conexión (Porcelli y Martínez, 2018). Esto

${ }^{16}$ La Constitución de la Nación Argentina, en los artículos 1, 5, 121 y 122 establece que las provincias conservan todo el poder no delegado al poder central. En este sentido, los servicios públicos son competencia de las provincias, aunque pueden ser excepcionalmente nacionales cuando presenten carácter interprovincial o internacional. La determinación y fijación de tarifas en sus jurisdicciones se definen a través de sus Direcciones Provinciales de Energía.

${ }^{17}$ Aproximadamente, entre $50 \%$ y $60 \%$ del costo de la tarifa de luz se compone por impuestos sobre distintos tramos de la cadena de valor, más otras ineficiencias y afectaciones a la productividad (CACME, 2019). 
ha llevado a que, al día de hoy, tan solo sean nueve las provincias que se adhieren plenamente a la ley: Catamarca, Córdoba, Corrientes, La Rioja, Mendoza, San Juan, Chubut, Tierra del Fuego y Tucumán. ${ }^{18}$

Los lineamientos técnicos y administrativos desglosados para el tipo de tarifa de inyección y la forma de medición no son solo puntos políticamente controversiales, sino también económicos. Aunque existen numerosas experiencias a nivel global, los instrumentos más aceptados se resumen a tres esquemas tarifarios. El más eficiente respecto a la divulgación rápida de estas energías, por reducción de costos y los incentivos que ofrece a los inversionistas, es el instrumento de las tarifas incrementadas del modelo alemán, denominado feed in tariff, donde el usuario-generador cobra un incentivo extra por cada $\mathrm{kW}$ inyectado.

Otro es el balance neto o net metering, donde el pago se deduce de la diferencia entre lo que se ha producido y lo que se ha consumido de la red de manera equitativa. El tercero es el esquema de balance neto de facturación o net billing, que difiere del balance neto en cuanto a que la energía inyectada por un particular y la comprada a la red tienen precios diferentes, establecidos por el estacional mayorista que deben pagar los distribuidores en el MEM y los minoristas que pagan los usuarios cautivos, respectivamente; este último es el adoptado por la ley nacional, mientras que algunos regímenes provinciales han optado por el instrumento tarifario del balance neto.

Santa Fe y Salta han reorientado su estrategia hacia un sistema de feed in tariff, y la legislación neuquina autoriza a la Autoridad de Aplicación establecer precios diferenciales durante distintos plazos (Sosa, 2017).

Estas diferencias son indisociables de los costos de la energía y la paridad de red en cada provincia, es decir, de las capacidades que tiene una instalación de GD de amortizar la inversión en un plazo corto. Por ejemplo, una reglamentación de balance neto en Buenos Aires podría ser amortizada en 21 años, a comparar con una vida útil promedio de los equipos de 20 años.

En el caso de un usuario de Santa Fe, que se beneficia de una radiación apenas mayor a Buenos Aires, esta amortización baja a 12 años (Sergent, 2018). Esta diferencia se explica por dos razones: el tipo de tarifa aplicado y la fuerte disparidad que persiste en las tarifas de luz entre provincias. En este sentido, los prosumidores santafesinos se benefician de un modelo feed in tariff que les ahorra el consumo de energía de red, más cara que la de su par en Buenos Aires. Esto podría ser contrarrestado con el Fodis,

\footnotetext{
${ }^{18} \mathrm{La}$ adhesión de las provincias a la normativa nacional brinda acceso a los fondos de incentivos creados en la ley: Fodis, FANSIGED (fondo de promoción industrial) y exenciones impositivas (IVA, Ganancias).
} 
que al financiar las instalaciones permite reducir los plazos de amortización y aumentar así los casos de paridad de red.

Sin embargo, desde varios sectores se argumenta que una cantidad exagerada de incentivos monetarios supone que los usuarios cautivos subsidien parte del costo de distribución a los usuarios microgeneradores, derivando en lo que en la jerga del sector se denomina "espiral de la muerte". Esto es, cuando los costos necesarios para operar y mantener las redes, producto del sobre-estímulo de la microgeneración se distribuyen entre, cada vez, una base menor de consumidores y una cantidad menor de $\mathrm{kWh}$ consumidos.

Más allá de los cuestionamientos de índole político, económico, legal y técnico, hoy existe un debate abierto sobre la microgeneración, en algunos casos con una fuerte decisión política. Pese a que la ley nacional propone una meta sumamente conservadora de mil megavatios de potencia instalada para 2030 ( $5 \%$ de las fuentes renovables si se toma el escenario tendencial para cumplir con la ley 27.191), esta es una tecnología incipiente cuyo grado de participación ciudadana necesariamente será resultado de una efectiva difusión en todos los niveles de gestión: federal, provincial y municipal.

Aun cuando la distribución de la energía es potestad de las provincias, una regulación nacional consensuada es necesaria para consolidar lineamientos técnicos y administrativos comunes que integren políticas energéticas de largo plazo y con un objetivo estratégico. Además, una vez adecuada la regulación, será un desafío central para las distribuidoras tomar la responsabilidad de poner en marcha nuevos modelos de negocio.

Bajo este paradigma energético, la dimensión social cobra un papel fundamental, ya que incluye a la ciudadanía en la transición energética ocupando un rol decisivo. Podemos decir que este nuevo paradigma fundamenta, desde un punto de vista filosófico y político, una condición inalienable de la ciudadanía, que es la libertad. Otorga la facultad de los usuarios de elegir y de tomar decisiones libremente y de independizarse tanto de la intervención estatal como del monopolio privado. Asimismo, se fomenta la competencia local a través de un círculo virtuoso: el usuario compra e instala equipos de generación, percibiendo menores gastos en sus tarifas eléctricas, lo que a su vez genera un movimiento de mercado que involucra tanto a fabricantes nacionales como proveedores e instaladores locales, una red que podría crear grandes cantidades de puestos de trabajo.

A fin de cuentas podría significar el destierro de las grandes corporaciones energéticas y el ascenso de un circuito financiero que inicia y finaliza en el mismo territorio. El hecho de que la generación, fundamentalmente la toma de decisión, se traslade a los grupos sociales más amplios 
empodera a los ciudadanos y las comunidades, convirtiendo todo el ciclo de la energía en más transparente, distributivo y democrático.

\section{Reflexiones finales: la transición energética como proyecto geográfico}

Actualmente, la forma en que se produce y consume la energía no es sostenible. En el lapso de la última centuria, el sistema energético argentino se fortaleció de la explotación de sus más asequibles y rentables recursos fósiles, apoyado en un proceso de concentración y centralización de la generación y distribución eléctrica no sólo en sus aspectos técnicos, sino también económicos, políticos y de propiedad. En esencia, la crítica al modelo energético fosilista resalta la importancia de este último. El sistema nacional se constituye por un entramado de empresas mayormente privadas, estatales y mixtas, consolidada en la década neoliberal de los noventa, el cual requiere una coordinación institucional muy fuerte para la planificación y operación centralizada, lo que ha provocado una dependencia efectiva de los territorios y usuarios finales respecto a los actores desterritorializados.

Este cuadro de situación no se ha alterado con la política energética traccionada por el programa RenovAr, que carece de una convicción ambientalista e industrialista mucho menos orientada a romper con el circuito de la renta energética hacia un desarrollo más desconcentrado y democrático. Al contrario, esta política relativamente descentralizadora y diversificadora de la matriz nacional trata de sentar las bases de un incipiente mercado en manos privadas, con un importante protagonismo de compañías energéticas y financieras transnacionales, donde los municipios y cooperativas quedaron marginadas, operando, en el mejor de los casos, apenas como oferentes de terrenos aptos para el desarrollo de proyectos.

Ahora bien, el impulso internacional que alienta un cambio de matriz a partir de tecnología de energía renovable se presenta no solo como una oportunidad para sustituir las energías fósiles contaminantes y mitigar las causas del calentamiento global, sino que se muestra también atrayente para avanzar hacia una transformación radical del sistema energético en su conjunto. En este sentido, la denominada transición energética se inscribe en una disputa entre dos modelos discordantes: una transición hacia renovables orientada al mercado, que replique el modelo actual fósil, y otra motorizada desde la órbita pública-ciudadana, que apuntale un sistema energético más equitativo, menos concentrado y más democrático. El quid de la cuestión recala en los alcances y las limitaciones que expresan los diferentes actores a la hora de pensar la descentralización geográfica con las energías renovables, y su capacidad de nutrirse del flujo energético local. 
La aplicación de las energías renovables de forma distribuida es un campo inmenso que aún no se ha explotado en Argentina, fundamentalmente porque la mayoría de las reglamentaciones provinciales no permitían a un particular tener una instalación de este tipo. Sin embargo, en esta nueva coyuntura, y a partir de lo desarrollado, este trabajo sostiene que son las empresas públicas, junto con las cooperativas eléctricas y los propios ciudadanos, quienes se posicionan al frente de nuevos modelos de gestión de la energía. Teniendo en cuenta esta hipótesis, y la calidad de los recursos solares y eólicos del territorio nacional, sumado también al estado crítico del sistema de transporte y la saturación de las líneas, la GD se presenta como una opción técnica de enorme potencial.

Ahora, cabe preguntarse ¿Quiénes más podrían beneficiarse de este proceso descentralizador? ¿Qué pasará con los tradicionales usuarios que no participan de este proceso? ¿Serán ellos los encargados de financiar la transición energética? ¿Transición energética para quién y para qué? ¿Es posible que se potencien nuevos procesos de marginalidad energética? Experiencias no muy distantes en Brasil, Chile y Uruguay dan cuenta de la potencialidad de este paradigma pero donde el estímulo económico ha resultado ser más sostenible que cualquier motivación política, lo que limita en cierto punto las promesas democratizadoras (Garrido, 2019).

Brasil ya supera los $500 \mathrm{MW}$ de potencia instalada (Aneel, 2019), mientras que en Uruguay y Chile alcanzan los $16 \mathrm{MW}$ y $24 \mathrm{MW}$, respectivamente (UTE, 2019; Systep, 2019). Más allá del éxito que pudieron tener los programas nacionales en términos cuantitativos, un análisis más detallado de estos procesos evidencia un aspecto no menor, que es el protagonismo de las empresas industriales, establecimientos comerciales y emprendimientos inmobiliarios en la proliferación de estas tecnologías de GD. Resulta menester, entonces, revisar otros tipos de modelos que superen a los basados en incentivos de mercado, o en el protagonismo excluyente del Estado nacional, los cuales contemplen múltiples actores y escalas imbricadas entre sí.

El principal desafío que ostentan los modelos alternativos es el del acceso al financiamiento, sobre todo porque las energías renovables son de capital intensivo. A partir de repasar diversas experiencias internacionales, podemos destacar tres mecanismos financieros que han tenido un importante grado de desarrollo. En Estados Unidos han primado los sistemas de crédito denominados Property Assessed Clean Energy (PACE). Estos son medios para financiar actualizaciones de eficiencia energética a través de hipotecas o gravámenes específicos, donde la propiedad del generador es del usuario o consorcio. También se ha expandido el modelo de financiamiento de terceros, que corresponde a empresas o privados que 
administran sistemas de GD en la propiedad de un tercero, fundamentalmente techos en zonas residenciales (Hess, 2013).

En Europa, por otro lado, el modelo cooperativo ha tenido una gran penetración, funcionando como sociedades de usuarios que comparten una unidad de generación. No obstante, gran parte de estas iniciativas tuvieron un alcance limitado, demostrando la imposibilidad de aplicar mecanismos universales, más aún en el caso argentino, donde las condiciones económicas dificultan el acceso a créditos blandos. Cabe destacar el modelo impulsado por la cooperativa de Armstrong, denominado "solidario" (Garrido, 2019), en el cual los vecinos aportan sus techos sin recibir ningún tipo de retribución económica, mientras que la cooperativa crea un fondo de reserva con el valor de la energía generada para reinvertir en nuevos equipos y extender el sistema.

Entonces, en este marco, una transición genuina y sustentable requiere contemplar procesos de adecuación que operan e interactúan en diferentes ámbitos y escalas, dando lugar a dinámicas más complejas (Unceta Satrústegui, 2009). Cuando hablamos de transición, hablamos de un proyecto fundamentalmente geográfico. El Estado nacional, las provincias y las empresas públicas cumplen un rol clave, especialmente en el aspecto regulatorio y económico, sentando las bases para que los actores locales (cooperativas, municipios, ciudadanos) puedan desenvolverse sin obstáculos. Más allá de que la ley 27.424 ayuda a cerrar una brecha jurídica que tenía el país respecto a los países de la región, la diversidad de los subsistemas sociales en el territorio nacional, permite vislumbrar una transición energética que requerirá de la articulación entre procesos locales y nacionales, entre lógicas de acción políticas y económicas.

Entre las virtudes que se les asignan a los sistemas distribuidos destaca la posibilidad de reducir la vulnerabilidad energética de las provincias, potenciar el rol de los actores territoriales, y brindarles mayor autonomía a los usuarios. Esto trae aparejados beneficios que resultan de gran importancia para el desarrollo del país como totalidad: el impulso de economías regionales, promoción del desarrollo industrial y tecnológico, aumento de la soberanía energética, e incremento de la eficiencia del sistema eléctrico a partir de aliviar la demanda y las pérdidas en las redes de transporte y distribución. Además, en contraste con los grandes parques eólicos y solares, se crearía una masa mayor de empleo. Esto es así ya que la generación a gran escala conlleva una mano de obra temporal contratada exclusivamente por la empresa desarrolladora, mientras que con la generación distribuida se genera una masa de trabajadores más numerosa, diversa y dispersa.

Para finalizar, es necesario reforzar la concepción de la energía como herramienta fundamental para el fortalecimiento de los mecanismos de redistribución de la riqueza, sobre todo ante un contexto de fuerte 
crecimiento de la pobreza energética en el país. El avance hacia la democratización de la generación debe ser sostenida con la democratización del consumo, es decir, el acceso universal a servicios energéticos asequibles, fiables y modernos para todos los que habitan el territorio nacional. El reconocimiento de que la generación de energía podría ser mucho más eficientemente organizada como un procomún, en lugar de como una mercancía, debe ser el principio fundamental subyacente a todas las propuestas de políticas alternativas para el sector energético. De acuerdo con este principio general, el modelo de energía distribuida permite identificar un conjunto de condiciones facilitadoras y potenciadoras para guiar los esfuerzos de formulación de políticas de abajo hacia arriba, y reforzar un metabolismo social basado en combustibles post-fósiles, que respete los derechos de la naturaleza y la sociedad, donde la energía ostenta una posición decisiva.

\section{Fuentes consultadas}

Aneel (Agencia Nacional de Energía Eléctrica de Brasil) (2019), “Geração distribuída”, Aneel, Brasil, <http://www2.aneel.gov.br/scg/gd/ GD_Fonte.asp $>, 10$ de mayo de 2019.

BOPJ (Boletin Oficial de la Provincia de Jujuy) (2017), "Ley Nº.023. Generación Distribuida de Energía Renovables", 25 de octubre de 2017, Jujuy, Dirección Provincial de Boletín Oficial e Imprenta del Estado/Gobierno de Jujuy, <http://www.consejosalta.org.ar/ wp-content/uploads/LEY-6023.pdf>, 26 de febrero de 2020.

BOPM (Boletin Oficial de la Provincia de Mendoza) (2013), "Ley № 7.822. Declara de interés provincial la generación de energía eléctrica a partir de fuente de energía alternativa", 1 de julio de 2013, Mendoza, Boletín Oficial, Provincia de Mendoza/Gobierno de Mendoza, <http://www.saij.gob.ar/853-local-mendoza-decre to-reglamentario-ley-7822-declara-interes-provincial-generacionenergia-electrica-partir-fuente-energia-alternativa-m 20130 000853-2013-06-12/123456789-0abc-358-0000-3102mvorpced>, 26 de febrero de 2020 .

BOPM (Boletín Oficial de la Provincia de Misiones) (2016), "Ley № 118 Balance Neto. Micro Generadores Residenciales, Industriales y/o Productivos", 12 de septiembre de 2016, Misiones, Dirección Boletín Oficial Provincia de Misiones, <http://cnpmweb.com.ar/ 
wp-content/uploads/2017/06/Ley-I-N118-antes-Ley-3743.pdf>, 26 de febrero de 2020.

BOPN (Boletín Oficial de la Provincia de Neuquén) (2016), "Ley N³.006. Generación distribuida mediante fuentes de energías renovables", 29 de julio de 2016, Neuquén, Poder Judicial de Neuquén, <http://200.70.33.130/images2/Biblioteca/3006.pdf>, 26 de febrero de 2020.

BOPS (Boletin Oficial de la Provincia de Salta) (2014), "Ley N 7.824. Balance Neto. Generadores Residenciales, Industriales y/o Productivos", 28 de julio de 2014, Salta, Secretaría General de la Gobernación, <http://boletinoficialsalta.gob.ar/VersionImprimibleLeyes.php?nro_ley2=7824>, 26 de febrero de 2020 .

BORA (Boletin Oficial de la República Argentina) (2017), "Ley N² 27424. Régimen de Fomento a la Generación Distribuida de Energía Renovable Integrada a la Red Eléctrica Pública”, 27 de diciembre de 2017, Buenos Aires, Congreso de la Nación Argentina, <http:// servicios.infoleg.gob.ar/infolegInternet/anexos/30500 0-309999/305179/norma.htm>, 26 de febrero de 2020.

BORA (Boletin Oficial de la República Argentina) (2015), "Ley N²7191. Régimen de Fomento Nacional para el uso de Fuentes Renovables de Energía destinada a la Producción de Energía Eléctrica. Modificación”, 21 de octubre de 2015, Buenos Aires, Congreso de la Nación Argentina, <http://servicios.infoleg.gob.ar/infolegInternet/anexos/250000-254999/253626/norma.htm>, 26 de febrero de 2020 .

BORA (Boletin Oficial de la República Argentina) (2012), "Ley N²6.741. Yacimientos Petrolíferos Fiscales", 7 de mayo de 2012, Buenos Aires, Congreso de la Nación Argentina, <http://servicios.infoleg. gob.ar/infolegInternet/anexos/195000-199999/196894/norma. htm>, 26 de febrero de 2020 .

BORA (Boletín Oficial de la República Argentina) (1960), "Ley N 15.336. Ley de Energía Eléctrica", 22 de septiembre de 1960, Buenos Aires, Congreso de la Nación Argentina, <http://servicios.infoleg. gob.ar/infolegInternet/anexos/25000-29999/28195/texact.htm>, 26 de febrero de 2020. 
BOSL (Boletín Oficial de San Luis) (2014), "Ley No 921. Promoción y Desarrollo de Energías Renovables", 31 de diciembre de 2014, San Luis, El Senado y la Cámara de Diputados de la Provincia de San Luis, <http://www.diputados.sanluis.gov.ar/diputadosasp/ paginas/verNorma.asp?NormaID=1003>, 26 de febrero de 2020.

CAMMESA (Compañía Administradora del Mayorista Eléctrico S. A.) (2019), "Informes Mensuales del MEM y del MEMSP.- enero de 2003 a noviembre de 2019", Buenos Aires, CAMMESA, <http:/ portalweb.cammesa.com>, 26 de febrero de 2020.

Carrizo, Silvina; Jacinto, Guillermina y Clementi, Luciana (2014), “Un siglo de desafíos, realizaciones y proyectos para las cooperativas eléctricas en la Provincia de Buenos Aires", Mundo Urbano, núm. 43, Buenos Aires, Universidad Nacional de Quilmes, pp.1-16.

Castelao Caruana, María (2016), "Impacts of bioenergy projects through Electrical cooperatives in Argentina", conferencia presentada en la Sexta Cumbre Internacional de Cooperativas, realizada del 11 al 13 de octubre, Quebec, Canadá, <https://www.researchgate. net/publication/309564816_Impacts_of_bioenergy_projects_ through_Electrical_cooperatives_in_Argentina>, 4 de diciembre de 2019.

CACME (Comité Argentino del Consejo Mundial de la Energía) (2019), "Los recursos energéticos distribuidos en Argentina: Contexto y Hoja de Ruta de Desarrollo Tecnológico", Informe sobre las Segundas Jornadas Nacionales de Actualización sobre los Desafíos Futuros de las Energías Renovables y la Generación Distribuida, Buenos Aires.

El Día (2004), "Un informe oficial advierte que puede faltar luz y agua", 20 de enero, La Plata, El Día S. A., <https://www.eldia.com/ nota/2004-1-20-un-informe-oficial-advierte-que-puede-faltarluz-y-agua>, 4 de diciembre de 2019.

Enarsa (Energía Argentina S.A.) (2009), "Programa para la Generación con Energías Renovables Genren”, Mendoza, Secretaría de Energía de la República Argentina, <http://www.energia.gov.ar/contenidos/archivos/Reorganizacion/novedades/EnergiasRenovables. pdf>, 26 de febrero de 2020 . 
Energías Renovables (2017), "La justicia de La Rioja paralizó las obras del parque solar fotovoltaico Nonogasta y 360Energy muestra sus argumentos", Energías Renovables, 9 de septiembre de 2017, $<$ https://energiasrenovables.com.ar/2017/09/09/la-justicia-de-larioja-paralizo-las-obras-del-parque-solar-fotovoltaico-nonogastay-360energy-muestra-sus-argumentos/>, 4 de diciembre de 2019.

Fornillo, Bruno (2017), "Hacia una definición de transición energética para Sudamérica: Antropoceno, geopolítica y podesarrollo", Prácticas de Oficio, 2 (20), Los Polvorines, Universidad Nacional de General Sarmiento, pp. 46-53

Furlán, Adriano (2017), "La transición energética en la matriz eléctrica argentina (1950-2014). Cambio técnico y configuración espacial”, Revista Universitaria de Geografía, 26 (1), Bahía Blanca, Universidad Nacional del Sur, pp. 97-133.

Garrido, Santiago (2019), "Desarrollo de sistemas de Generación Distribuida con Energías Renovables (GDER) en América del Sur. Alternativas para la Transición energética justa”, ponencia presentada en las $\mathrm{X}$ Jornadas de Sociología, 30 y 31 de mayo, Los Polvorines, Universidad Nacional de General Sarmiento, Argentina.

Garrido, Santiago; Lalouf, Alberto y Santos, Guillermo (2016), "Energía eólica de alta potencia en Argentina. Análisis socio-técnico de su trayectoria (1990-2015)", ponencia presentada en las XI Jornadas Latinoamericanas de Estudios Sociales de la Ciencia y la Tecnología, 25 al 28 de julio, Curitiba, Brasil.

Garrido, Santiago, Lalouf, Alberto y Moreira, Josefina (2013), “Implementación de energías renovables como estrategia para modificar la matriz energética en argentina. De las políticas puntuales a las soluciones sistémicas", Avances en Energías renovables y Ambiente, vol. 17, San Miguel, Asociación Argentina de Energía Solar, pp. 1235-1241.

Goldstein, Evelin; Kulfas, Matías; Margulis, Diego y Zack, Guido (2016), "Efectos macroeconómicos del sector energético en la Argentina en el período 2003-2014", Realidad Económica, 16 (298), Ciudad de Buenos Aires, Instituto Argentino para el Desarrollo Económico, pp. 32-79. 
Guido, Luciana, y Carrizo, Silvina (2016), "Innovaciones tecnológicas en 'redes eléctricas inteligentes': políticas públicas y experiencias locales en Argentina”, L’Ordinaire des Amériques, núm. 221, Toulouse, Université Toulouse,

Hawken, Paul; Lovins, Amory y Lovins, Hunter (1999), Natural capitalism: creating the next Industrial Revolution, New York, Little, Brown y Company.

Hess, David (2013), "Industrial fields and countervailing power: The transformation of distributed solar energy in the United States", Global environmental change, 23 (5), Ámsterdam, Elsevier, pp. 847-855.

IEA (International Energy Agency) (2018), "World Energy Outlook. Resumen ejecutivo", París, OCDE/AIE, <https://webstore.iea. org/download/summary/190?fileName=Spanish-WEO-2018-ES. pdf $>, 4$ de diciembre de 2019.

IPCC (Grupo Intergubernamental de Expertos sobre el Cambio Climático) (2016), "Informe de la Conferencia de las Partes sobre su 21 er periodo de sesiones", 30 de noviembre-13 de diciembre de 2015", Nueva York, IPCC, <https://unfccc.int/resource/ docs/2015/cop21/spa/10a01s.pdf/>, 26 de febrero de 2020.

Irena (International Renewable Energy Agency) (2018), "Community energy: broadening the ownership of renewables", Abu Dabi, IRENA, <https://coalition.irena.org/-/media/Files/IRENA/ Coalition-for-Action/Publication/Coalition-for-Action_Community-Energy_2018.pdf>, 4 de diciembre de 2019.

Irena (International Renewable Energy Agency) (2019), "Renewable Energy Market Analysis: GCC 2019”, Abu Dhabi, Irena, <https://www. irena.org//media/Files/IRENA/Agency/Publication/2019/Jan/ IRENA_Market_Analysis_GCC_2019.pdf>, 5 de febrero de 2020.

Martínez, Adriana y Porcelli, Adriana (2018), "Análisis del marco legislativo argentino sobre el régimen de fomento a la generación distribuida de energía renovable integrada a la red pública”, Lex Social: Revista de Derechos Sociales, 8 (2), Sevilla, Universidad Pablo de Olavide de Sevilla-Centro Euro-Árabe de Estudios Jurídicos Avanzados, pp. 179-198.

Mumford, Lewis (1977), “Técnica y Civilización”, Madrid, Alianza. 
Pendón, Manuela; Williams, Eduardo; Cibeira, Natalia; Couselo, Romina; Crespi, Gabriel y Tittonel, Marcelo (2017), "Energía renovable en Argentina: cambio de paradigma y oportunidades para su desarrollo", ponencia presentada en las IV Jornadas de Investigación, Transferencia y Extensión, 4-6 de abril, La Plata, Universidad Nacional de La Plata, <http://sedici.unlp.edu.ar/bitstream/ handle/10915/60384/Documento_completo.pdf-PDFA. pdf?sequence $=1$ \&isAllowed $=y>, 4$ de diciembre de 2019 .

Porcelli, Adriana, y Martínez, Adriana (2018), "Una inevitable transición energética: el prosumidor y la generación de energías renovables en forma distribuida en la legislación argentina nacional y provincial", Actualidad Jurídica Ambiental, núm. 75, Madrid, Centro de Investigaciones Energéticas, Medioambientales y Tecnológicas-Centro Internacional de Estudios de Derecho Ambiental, pp. 4-49.

RenovAr (2016), "Programa de Energías Renovables", Ministerio de Energía y Minería, <https://www.minem.gob.ar/www/706/24712/ articulo/noticias/1237/el-presidente-lanzo-elprograma-renovarde-energias-renovables.html>, 26 de febrero de 2020.

Schumpeter, Joseph (1957), Teoría del desenvolvimiento económico, Ciudad de México, Fondo de Cultura Económica.

Sergent, Adrien (2018), "Generación distribuida: ¿en vísperas de una revolución copernicana?", Revista argentina de derecho de la energia, hidrocarburos y minería (RADEHM), núm. 17, Buenos Aires, Editorial Ábaco de Rodolfo Depalma, pp. 187-196

Singh, Nanda (2019a), "Empresarios y funcionarios en debate: cómo desarrollar la industria nacional en la generación distribuida”, Energía Estratégica, 29 de abril de 2019, <https://www.energiaestrategica.com/empresarios-y-funcionarios-en-debate-comodesarrollar-la-industria-nacional-en-la-generacion-distribuida/>, 4 de diciembre de 2019.

Singh, Nanda (2019b), "Intermepro inaugura hoy el parque solar más importante de Entre Ríos", Energía Estratégica, 24 de mayo de 2019, <http://www.energiaestrategica.com/intermepro-inaugurahoy-el-parque-solar-mas-importante-de-entre-rios/>, 4 de diciembre de 2019. 
Singh, Nanda (2019c), "Instalaron una turbina eólica experimental en Tierra del Fuego", Energía Estratégica, 10 de junio de 2019, $<$ http://www.energiaestrategica.com/instalaron-turbina-eolicaexperimental/>, 4 de diciembre de 2019.

Singh, Nanda (2019d), "La Cooperativa de Electricidad Bariloche suma en su cartera tres proyectos renovables y avanza con conexiones de prosumidores", Energía Estratégica, 15 de agosto de 2019, $<$ http://www.energiaestrategica.com/la-cooperativa-de-electricidad-bariloche-suma-en-su-cartera-tres-proyectos-renovables-yavanza-con-conexiones-de-prosumidores/>, 4 de diciembre de 2019.

Singh, Nanda (2018a), "EPEC define proyectos de renovables en Córdoba: ahora negocia precios con proveedores para desarrollar parques solares", Energía Estratégica, 27 de diciembre de 2018, <http:// www.energiaestrategica.com/epec-define-proyectos-de-renovables-en-cordoba-ahora-negocia-precios-con-proveedores-paradesarrollar-parques-solares/>, 4 de diciembre de 2019.

Singh, Nanda (2018b), "Es oficial: el Gobierno de Chaco lanza una nueva licitación llave en mano para la construcción de un parque solar fotovoltaico", Energía Estratégica, 4 de diciembre de 2018, <http:// www.energiaestrategica.com/es-oficial-el-gobierno-de-chacolanza-una-nueva-licitacion-llave-en-mano-para-la-construccionde-un-parque-solar-fotovoltaico/>, 4 de diciembre de 2019.

Sosa, María Isabel (2017), "Cogeneration within the New Regulations on Distributed Generation", documento presentado en el XII Latin-american congress on electricity generation and transmission, 12-15 de noviembre, Mar del Plata.

Systep (2019), "Reporte mensual del sector eléctrico", Santiago de Chile, Systep, <http://www.systep.cl/documents/reportes/042019_Systep_Reporte_Sector_Electrico.pdf>, 4 de diciembre de 2019.

Torres Cabreros, Delfina (2019), “Santa Fe toma la delantera en energías renovables y lanza su propia licitación”, Diario La Nación, 12 de febrero, Buenos Aires, <https:/www.lanacion.com.ar/economia/ con-licitacion-historica-santa-fe-busca-inversiones-nid2219453>, 4 de diciembre de 2019.

Unceta Satrústegui, Koldo (2009), "Desarrollo, subdesarrollo, maldesarrollo y postdesarrollo: una mirada transdisciplinar sobre el debate 
y sus implicaciones", Carta Latinoamericana, núm. 7, Montevideo, Centro Latino Americano de Ecología Social, pp. 1-34.

UTE (Usinas y Trasmisiones Eléctricas) (2019), “Consulta geográfica por fuentes de generación”, Montevideo, UTE, <https://portal.ute. com.uy/institucional/infraestructura/fuentes-de-generacion>, 4 de diciembre de 2019.

Vitale, Mario (2010), "La problemática de las cooperativas prestadoras del servicio eléctrico en la Argentina", en Seminario de Actualización de Políticas Públicas, Movimiento Productivo Argentino, 13 de abril de 2010, Buenos Aires, Argentina.

Verbitsky Horacio (2019), "Agua para sus molinos”, El cohete a la luna, 20 de enero de 2019, <https://www.elcohetealaluna.com/agua-parasus-molinos/>, 4 de diciembre de 2019.

World Bank (2012), "Incorporating green growth and sustainable development policies into structural reform agendas", vol. 1, Washington, World Bank, <http://documents.worldbank.org/curated/ en/274111468157530491/Incorporating-green-growth-andsustainable-development-policies-into-structural-reform-agendas $>, 4$ de diciembre de 2019.

Recibido: 14 de octubre de 2019. Reenviado: 22 de enero de 2020. Aceptado: 20 de febrero de 2020.

Martín Kazimierski. Doctorando en Geografía por la Universidad de Buenos Aires (UBA). Actualmente es investigador en formación del Instituto de Estudios de América Latina y el Caribe (IEALC-UBA) y becario del Consejo Nacional de Investigaciones Científicas y Técnicas (Conicet). Sus líneas de investigación abordan el sistema energético argentino, con especial énfasis en los procesos de incorporación de energías renovables. Entre sus últimas publicaciones destacan: como autor, “Transición energética, principios y retos: la necesidad de almacenar energía y el potencial de la batería ion-litio", en Bruno Fornillo (coord.), Litio en Sudamérica Geopolitica, energía y territorios, Buenos Aires, El Colectivo-CLACSO, pp. 25-49 (2019); en coautoría, "Modelos de trabajo en la interdisciplina: un análisis relacional de los espacios de frontera", Redes. Revista Hispana para el Análisis de Redes Sociales, 30 (1), Barcelona, Universidad Autónoma de 
Barcelona, pp. 25-42 (2019); como autor, "Almacenamiento energético frente al inminente paradigma renovable: el rol de las baterías ion-litio y las perspectivas sudamericanas", Letras Verdes. Revista Latinoamericana de Estudios Socioambientales, núm. 23, Quito, FLACSO, pp. 108-132 (2018). 